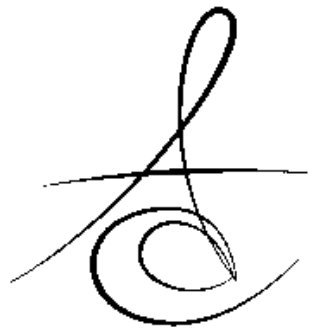

\title{
ÇENE YÜZ PROTEZLERİNDE KULLANILAN MATERYALLERİN GELİŞİMİ VE ÖZELLİKLERİ
}

\section{DEVELOPMENT AND PROPERTIES OF MATERIALS USED IN MAXILLOFACIAL PROSTHESIS}

\author{
Arş.Gör.Dt.Kübra DEĞİRMENCİ* Yrd.Doç. Dr. Serkan SARIDAĞ ${ }^{*}$
}

Makale Kodu/Article code: 2173

Makale Gönderilme tarihi: 06.03.2015

Kabul Tarihi: 01.07.2015

\section{ÖZET}

Çene yüz protezleri çeşitli sebeplerle meydana gelen defektler sonucunda bozulan bütünlüğün iyileştirilmesi amacıyla yapılan protetik uygulamalardır. Bu protezlerin yapımında kullanılan materyallerin sahip oldukları özellikler; estetik dayanıkılık ve hasta konforunu önemli ölçüde etkiler. Çene-yüz protezlerinde başarının sağlanabilmesi, protez yapımında vakaya uygun özellikte materyallerin kullanılması ile mümkündür. Yapılan bu derleme çalışmasında çene-yüz protezlerinin gelişimine değinilmiş ve günümüzde çene-yüz protezlerinde kullanılan materyallerin özellikleri avantaj ve dezavantajları ile açıklanmıştır.

Anahtar Kelimeler: Çene-yüz protezleri, elastomerler, silikonlar, renk pigmentleri.

\section{GİRİŞ}

Çene yüz bölgesindeki yapıların bütünlüğünün herhangi bir sebeple bozulması sonucu çene yüz defektleri oluşur. ${ }^{1} \mathrm{Bu}$ sebeplerin arasında hemifasiyal mikrozomi gibi doğumsal veya tümör, travma gibi edinsel durumlar sayılabilir. ${ }^{2-5}$ Tıp alanındaki gelişmeler neticesinde kanser vakalarının iyileşmelerindeki artış ve sağkalım sürelerinin uzaması ile beraber çene yüz protezleri vakalarında da artışlar görülmektedir. ${ }^{6}$ Çene yüz protezinin amacl; hastanın kaybolan çiğneme, solunum, yutkunma gibi fonksiyonlarını hastaya kazandırmanın yanında kaybolan estetik ve olumsuz etkilenen sosyal durumunun da iyileştirilebilmesidir.

Çene yüz defektlerinin tedavisi, multidisipliner bir çalışmayı gerektirebilir. Baş boyun cerrahisi, rekonstruktif cerrahi, ortodonti ve protez bölümlerinin beraber çalışması tedavi başarısını arttırır. ${ }^{7}$ Cerrahi ile

\section{ABSTRACT}

Maxillofacial prosthetics are made in order to improve the integrity of the prosthetic deteriorated as a result of defects that occur for various reasons. They have characteristics of materials used in the construction of this prosthesis; aesthetics and durability significantly affect patient comfort. To ensure the success of maxillo-facial prostheses, in appropriate cases feature the prosthesis is possible with the use of materials. It mentioned in this compilation work done on the development of maxillofacial prosthesis, and today is explained by the characteristics of the advantages and disadvantages of materials used in maxillofacial prosthetics.

Key Words: Maxillofacial prosthetic materials, elastomers, silicones, colored pigment

defektli alanların rekonsturksiyonu yapılarak hastanın kendi dokusu ile tedavisi mümkündür ancak cerrahi uygulanamayan bazı durumlarda protetik rehabilitasyon kaçınılmazdır. Hastanın kendi dokusu ile kapatılamayacak kadar geniş defektlerinin olduğu durumlarda, ışın tedavisi sonrası defekt varlığında, hastanın sistemik durumunun izin vermediği vakalarda çene yüz protezleri hastalar için çözüm olabilir. ${ }^{8,9}$ Protetik uygulamalar, ekonomik olması, bölgenin temizlenmesine ve periyodik olarak değerlendirilmesine imkan tanıması gibi cerrahi yaklaşımlara göre birtakım avantajlara da sahiptir. ${ }^{10}$

Çene Yüz Protezlerinde Kullanılan Materyallerin Gelişim Süreci

Geçmişten günümüze kadar çene-yüz protezlerinde fildişi, ağaç, mum, cam, kumaş, deri, metal, vulkanit, porselen, kauçuk, lateks ve akrilik rezin gibi çok farklı malzemelerin kullanıldığı görülmüştür. Araştırmacılar çeşitli materyalleri kaybolan dokuların fonksi-

\footnotetext{
* Kocaeli Üniversitesi, Diş Hekimliği Fakültesi, Protetik Diş Tedavisi Anabilim Dalı
} 
yonlarını geri kazanabilmek için kullanmayı amaçlamışlar ve 1800 lü, 1900 lü yıllarında yöntem olarak nazal defektleri seramik materyal ile rehabilite etme metotlarını geliştirilmiştir. ${ }^{6,11}$

1868 yılında ilk organik plastik kalıp materyali olan selüloz nitratı üreterek plastik çağın başlamasını sağla- mıştır. ${ }^{12,13}$ Birinci dünya savaşı çene yüz protezlerine artan ihtiyaç ile beraber yeniliklerin uygulandığı bir dönemdir. Esas olarak çene yüz protezlerinin üretil- mesinde sert materyallerden yumuşak ve elastik ma- teryallere geçiş büyük bir ilerlemedir ve bu ilerleme canlı dokuya daha çok benzeyen protezlerin üretilebilmesini olanak sağlamıştır. ${ }^{6}$

Nazal ve oküler protezlerde plastik yapının kullanımı 1930 yılında geliştirilmiş, bu sayede vulkanit protezlerin de yapımına başlanmıştır. Akrilikten yapılan göz protezleri 1934-1944 yılları arasında kullanılmış ve akriliğe olan ilginin arttığı gözlenmiştir. ${ }^{13}$ Akrilik rezin, kolay işlenebilmesi, translusens olması ve renklendirilebilme özellikleri ile bu dönemde klinisyenlerin dikkatini çekerek önceki dönemde kullanılan vulkanitin önüne geçmiştir. ${ }^{14}$

Silikon materyaller ilk kez 1946'lı yıllarda Barnhart ve arkadaşları tarafından çene yüz protez yapımında kullanılmaya başlanmıştır. ${ }^{15}$ Çene yüz protezlerinin üretiminde kullanılan elastomerlerin 1960 ve 1970'li yıllarda çeşitli türleri geliştirilmiştir. Gonzalez adlı araştırmacı 1990 yılında poliüretanı tanımlarken, aynı yıllarda da Lontz adlı araştırmacı polisilokan elastomerin değiştirilen türlerini kullanarak materyallerin gelişimine önemli katkılar sağlamıştır. ${ }^{16,17}$ Ancak marjinlerde yırtılma direncinin zayıflığı, elastik modülüs değerlerinin farklılıkları, aşırı su absorbsiyonu ve tükrük ile ıslanabilirlik gibi özelliklerin yetersizliği dönemin çalışmalarıyla da ortaya konulmuştur. 2,18,19

Amerikan Çene Yüz Protez Derneği 1966 yılında çene yüz protez materyallerinin özelliklerini araştırmış ve ideal materyal özelliklerini Washington'daki bir toplantıda meslektaşlara ve kamuoyuna duyurmuştur. Çene ve yüz protezlerinde kullanılan materyallerde bulunması istenen özellikler: :2,20-22 $^{2}$

1.Doku uyumluluğu olmalı,

2.Dokunun gerçek tonlarını yakalayabilmeli, 3.Şeffaf olabilmeli,

4.Yumuşak dokuları taklit edebilecek kadar esnek olabilmeli,

5.Dış etkenlere soğuk, sıcak, güneş ışığı vb. karşı koyabilecek dayanıklılıkta olmalı,

6.Isıyı geçirebilme özelliği düşük olmalı,

7.Hafif olmalı,

8.İşlenebilmeli veya kalıplanabilmeli, 9.Uygulaması kolay olmalı, 10. Kolayca kopyalanabilir,

11.Kolay temizlenebilir olmalı şeklinde özetlenmiştir.

Beumer ve ark. ${ }^{23} 1996$ yılında ideal çene yüz protez materyallerinin özelliklerini fiziksel ve mekanik özellikler, işlenme özellikleri ve biyolojik özellikler olmak üzere üç bölüme ayırarak incelemişlerdir. Araştırmacıların belirtiği kriterler arasında 1966'daki kriterlere ilaveten renk stabilitesi, kenar bütünlüğü ve dayanıklılığı, materyalin kullanım kolaylığı, materyalin maliyeti, yeniden üretime gerek duyulmadan ayarlama yapılabilmesi, toksik olmaması ve kısa sürede üretilebilmesi de bulunmaktadır. $23-25$

Belirlenen ideal kriterlerin hepsini sağlayabilen bir materyal henüz piyasada bulunmamaktadır ve geliştirilmeye devam edilmektedir ${ }^{12,26,27}$

\section{Çene Yüz Protezlerinde Kullanılan Materyallerin Özelikleri \\ 1Akrilik Rezin:}

Akrilik rezinler, özellikle ikinci dünya savaşı döneminde camdan yapılan göz protezlerinin yerine kullanılmaya başlanmıştır. Akrilik rezinler, fonksiyon sırasında protezin defekt içinde fazla hareketli olmadığı, doku yatağının az işlev gördüğü vakalarda tercih edilir ve aşırı hareketliliğin varlığında fiziksel irritasyona neden olabilir. Özellikle intraoral obturatör ve oftalmik protez yapımında tercih edilir. Toz kısmında polimetilmetakrilat Sıvı kısmında metil-metakrilat intiva ederler. $^{28}$

Avantajları: Dayanıklıdır, renk stabiliteleri iyidir, kozmetik özellikleri tatminkârdır, tamir edilebilir ve yenilenebilirler, uzun raf ömürleri vardır.

Dezavantajları: Su emiliminden dolayı bir hafta sonra ağırlıkları \% 0.5 oranında artar. Sert ve ağır olması, yüz hareketlerinde esnememeleri ve deri hissi vermemeleri en önemli dezavantajlarıdır. Yapım sürecinde basınçı teknikler kullanıldığında kalıbın zarar görmesinden dolayı protezin kopyalanabilmesi zordur. ${ }^{6,29}$ 


\section{2)Akrilik Ko-Polimerler:}

Akrilik monomer, oligomer ve polimerlerin yeni jenerasyonlarının geliştirilmesi ile metakrilatın bir türünü içeren akrilik ko-polimerler kullanılmaya başlanmıştır. Ancak geliştirilmesi gereken fiziksel özelliklerinden dolayı uygulama alanları yaygın değildir. ${ }^{28}$

Avantajları: Yumuşak ve elastiktirler, kolayca polimerize olurlar.

Dezavantajları: Kenar dayanıklılıkları zayıftır, güneş ışı̆ına maruz kalınca materyalin fiziksel özelliklerinde bozulma görülebilir, renklendirme işlemleri zordur, tamamlanan restorasyonlar toz toplamaya ve renklenmeye yatkındır. ${ }^{30}$

\section{3)Polivinil Klorid Ko-Polimer:}

Monomer vinilkloridin polimerizasyonu ile üretilen materyal içine renklendirici pigment eklenerek oldukça yaygın olarak kullanılmıştır. ${ }^{6}$ Ancak polimerizasyon ve kullanım sonrasındaki yan ürünlerinin toksik etkilerinin ortaya çıkmasından dolayı materyalin kullanım yaygınlığı giderek azalmıştır. ${ }^{12}$

Avantajları: Reaktör ve katalist oranları değiştirilerek esneklik ve renk adaptasyonu özellikleri değiştirilebilinir.

Dezavantajları: İçeriğindeki plastizörün erken kaybı; protez renginde solmaya, geçirgenliğinin artmasına ve vücut sekresyonlarının absorbe edilmesine neden olur ve sıvı absorbsiyonu kenarların erken yırtılmasına, fiziksel özelliklerin çabuk bozulmasına yol açar. $^{30}$

\section{4)Klorlu Polietilen:}

Lewis ve Castleberry ${ }^{31}$ klorlu polietilen materyalinin hem kimyasal yapı hem fiziksel özellikler açısından polivinil-kloride benzer olduğunu bildirmişlerdir. Daha düşük sıcaklıklarda termoplastik versiyonu 1976-1979 yılları arasında test edilmiştir. ${ }^{10}$ İşleme prosedürü, metal kalıplarda yüksek ısıda pigmentli yapraklarla gerçekleştirilir. Geliştirilen ve üzerine araştırmalar yapılan çene yüz protezinde kullanılan materyallerden biridir.

Avantajları: Silikon elastomerle kıyaslandığında 25,32 :

-Daha yüksek yırtılma dayanımı ve kenar dayanıklıı̆ıına sahiptir,

-Dönen aletlerle daha kolay uyumlama yapılabilir,

-Mikroorganizma gelişimine karşı dayanıklı olduğu tespit edilmiştir,

-Ekonomiktir,

-İçsel renklenme yapılmasına olanak sağlar,
-Daha kısa sürede yapımı tamamlanabilir.

Dezavantajları: Silikon elastomerlerle karşılaştırıldığında, bazı dezavantajları söz konusudur ${ }^{25}$ : -Yapım tekniği daha zordur, -İşlenmesi sırasında kırılabilir, çatlak oluşabilir, -Daha sert bir yapıdadır bu nedenle konforlu değildir, -Renk eşleşmesi ve görüntüsü silikonlar kadar iyi değildir, -Renk stabilitesi silikonlar kadar iyi değildir.

\section{5)Poliüretan Elastomerler:}

İki fonksiyonel grubun birleşiminden meydana gelen polimer yapıda materyallerdir. Bu gruplardan biri; iki veya daha fazla sayıdaki geliştirilmiş isosiyanat fonksiyonel grubu ve diğeri ise iki veya daha fazla sayıda hidroksil grubu içerir. Bu materyaller oda sıcaklığında sertleşebilmektedirler. Materyalin yapısında katalizör olarak dibutilindiuretan veya kalayoktat bulunabilmektedir. ${ }^{28}$ Epithane-3 ve Calthane günümüzde kullanılan ticari marka poliüretan elastomerlerdir. $^{33}$

Avantajları: Dayanıklılığa zarar vermeden elastikiyet gösterebilmeleri, içten ve dıştan renklendirilebilme özellikleri başlıca avantajlarıdır.

Dezavantajları: Reaksiyon nemsiz ortamda gerçekleşmelidir aksi takdirde karbon dioksit oluşumu gerçekleşecek ve elastomerin yapısında poröz oluşumu görülecektir. ${ }^{33}$ İçeriğindeki izosiyanat hidrofiliktir ve nemi absorbe ederek yapının özelliklerini etkileyecek hava kabarcıklarının oluşumuna neden olabilir. İşlenmesini zordur, yapıdaki plastizör kaybından dolayı renk stabilitesi iyi değildir. Adheziv sistemlerle uyumluluğu zayıftır. Yumuşak polimer yapılarından dolayı ince kenarların üretimine izin verecek yeterlilikte elastik özelliklere sahiptir. ${ }^{6}$ Ayrıca yapısında bulunan di-isosiyonat molekülünün toksik etkileri de olabilmektedir. ${ }^{34}$

\section{6)Silikon Elastomerler:}

Silikon sözcüğü polidimetilsiloksan PDMS türevleri ve öncelikli içerikleri PDMS olan bileşikler için kullanılır. Silikon, doğada kum ve kayalarda genellikle silika ve silikat formunda bulunur. Polisiloksanlar genel oksidatif ve termal bozunmaya karşı oldukça dirençli, kararlı bileşiklerdir. Özellikle $-50{ }^{\circ} \mathrm{C}$ ile $+70{ }^{\circ} \mathrm{C}$ sıcaklık aralığında elastik ve mekaniksel özelliklerini korurlar. ${ }^{35}$

Günümüzde çene yüz protezlerinin ekstraoral uygulamaları için en sık kullanılan materyaldir. Çünkü fiziksel özellikleri dokulara uyum sağlanması açısından uygundur. Silikon ve oksijen atomlarının değiştiği moleküler zincirlere dayalı organo-silikon sentetik

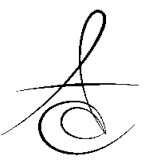


materyal türüdür. Elastomerik silikonlar sodyum ve çeşitli organik grupların silikon atomlarına eklenmesi veya moleküler zincirlerin çapraz bağlanması ile değiştirilebilen oksijen zincirlerinden oluşur. ${ }^{6}$ Translusent yapısı estetik beklentileri yerine getirmede olumlu katkı sağlar. Ayrıca doku uyumu iyi olmakla birlikte, hem iç hem de dış renklendirmeye uygundur. 8,36,37

Yapısındaki doldurucu oranı ve polimer zincirinin uzunluğu silikonun viskozitesini etkiler, uzun zincirler arasındaki çapraz bağlar ise ısıya karşı olan dayanıklığı etkiler. Genel olarak dayanıklııkları istenilen seviyede olmamasına ve yüksek ağırlık sorunlarına rağmen modern bir çene-yüz protez materyali olarak tercih edilirler. ${ }^{6}$

Polimerizasyon, monomer bileşenlerinin kimyasal yolla bir araya gelip daha yüksek molekül ağırlıklı polimerlerin oluşturduğu reaksiyona verilen isimdir. ${ }^{38,39}$ Uzun zincirli polimerler çeşitli bölgelerden birbirine bağlanarak sağlam bir iskelet yapı meydana getirir ve bu şekilde polimerlerin çapraz bağlanmasına vulkanizasyon denir. ${ }^{23}$ Silikonlar yüksek viskoziteli katı bir yapı oluşturmak için vulkanize edilirler. Çene yüz protezlerinin yapımında genellikle ISı ile vulkanize olan silikonlar tercih edilmektedir. Vulkanizasyon ISISI 150$220^{\circ} \mathrm{C}$ arasındadır ve metal muflalar ile gerçekleştirilir. $^{40}$ Silikonların çeşitli sıcaklıklarda sertleşme reaksiyonları vardır. Oda sıcaklı̆ında vulkanize olanlar RTV ve yüksek sıcaklıkta vulkanize olan silikonlar HTV olmak üzere ikiye ayrlırlar. ${ }^{41}$

\section{SilikonlarRTV:}

I.Oda Sıcaklığında Vulkanize Olan

Çene yüz protez yapımında kullanılan elastomerik materyaller arasında en iyi seçenek olarak tarif edilmişlerdir. Oda sıcaklığında vulkanize olan silikonlar yapısındaki çapraz bağın oluşumunun kondensasyon tipi reaksiyon veya ilave tipi reaksiyon ile gerçekleşmesine göre esas olarak iki çeşittir. RTV tip silikonlar, vinil ve hidrit içeren siloksanlardan oluştuğu ve kloroplatinik asit katalizörüyle polimerize olduğu için ilave tipli silikon ölçü maddeleriyle büyük benzerlik gösterir ve alçı kalıplarda polimerize edilebilirler. ${ }^{29,42}$

Doldurucu olarak di atom yapıda toprak parçacıkları içerir ve katalistik etki kalay oktat ile sağlanır. Translusens protez yapımına imkan sağlarlar. 6,30,33 Katalizörle mevcut elastomerin karıştırıması sırasında hava kabarcıkları ortaya çıkabilir. Bu kabarcıklar yırtılmaya ve deri üzerindeki sıvıların oluşan boşluklarda birikmesine neden olabilir. Yırtılma ilk olarak çentik ve boşlukların olduğu alanlarda başlar ve protez boyunca ilerler. Tamir edilmeleri oldukça zordur. Çekme gerilimini arttırmak, sararma ve renk bozulmasını engellemek için silika doldurucular ilave edilebilir. ${ }^{43}$

Silastic 382, 399, MDX4-4210 ve cosmesil marka ticari ürünler bu gruptadır.

Silastic 382,399:Renk stabilitesi iyidir, işlenebilirliği kolay, renklendirmeleri zor, dayanıklılıkları ise zayif materyallerdir. ${ }^{11,12}$

MDX4-4210:Adhezivler ile kullanıma uygundur. Renk stabilitesi ve sertlik özellikleri geliştirilmiştir.

Cosmesil: Wolfardt tarafından geliştirilen ilave silikon tipi çene yüz protezlerinde ürün yaygın şekilde kullanılmaktadır. ${ }^{44}$ İlave tipi silikon olması daha az poröz yapıda olmasını; dolayısıyla su absorpsiyon miktarının kondensasyon tipi silikonlara göre az olmasını olanaklı kılmaktadır. Su absorpsiyon miktarının az olması materyalin renk uyumunu olumlu yönde etkilemesi açısında önemlidir. ${ }^{45,46}$

Yüksek yırtılma direnci öne çıkmaktadır ve değişen sertlik derecelerinde üretilebilmektedirler. Cosmesilin MDX4-4210'dan daha yüksek yırtılma direncine sahip olduğunu gösteren çalışmalar vardır. ${ }^{28}$

Avantajları: RTV silikonlarda iç boyama tekrarlanabilir, işlenebilirlikleri HTV silikonlara göre daha kolaydır. Kimyasal özelliklerini yüksek ISI farklılaşmalarında koruyabilirler. Yarı şeffaf protezlerin yapımını mümkün kılarlar, biyolojik olarak inert yapıda olmalarıda RTV silikonların genel avantajları olarak sıralanmaktadır. 6,33

Dezavantajları: HTV silikonlara göre kenar dayanımının zayıflı̆ı̆, maliyetinin yüksek olması, poliüretan, akrilik rezin ve polivinil kloride göre daha az kozmetik olmaları başııca dezvantajlarıdır. ${ }^{6,33}$

\section{SilikonlarHTV \\ II.Yüksek Sıcaklıkta Vulkanize Olan}

HTV silikonlar genellikle beyaz, opak materyaller olup macun kıvamında, viskozitesi yüksek malzemelerdir. ${ }^{29} \% 0.5$ oranında vinil yan zincir yapısına sahip polidimetilvinil siloksan içeriklidir. Vulkanizasyon ilave tipi reaksiyon sonucunda meydana gelmektedir. Platinyum tuzları katalizör olarak işlev göstermektedir. Vulkanizasyonları $180-220{ }^{\circ} \mathrm{C}$ sıcaklıkta, basınç altında ve ortalama 30 dakika gibi bir sürede gerçekleşir. ${ }^{44}$

Yüksek yırtılma direnci gereken durumlarda tercih edilir. Yırtılma direnci üzerinde içeriğindeki 
katalizör, çapraz bağın yapısı ve tipi etkilidir, RTV ye göre daha serttir.

Silastik 382 ve 399 Michigan: En çok kullanılan ticari marka HTV silikonlardır. Silastik 382 bal gibi visköz kıvamda beyaz, opak ve akışkan özellik gösterirken, Silastik 399 beyaz vazeline benzer manipule edilebilir ama akışkan olmayan yapıdadır.

Avantajları: HTV silikonlar, RTV silikonlara göre daha iyi fiziksel ve mekanik özelliklere sahiptirler. Çok iyi Isısal stabilite göstermeleri, rengin stabil kalması, biyouyumlu olmaları en büyük avantajlarıdır. ${ }^{6}$

Dezavantajları: Yapım aşamaları yönünden RTV silikonlardan daha fazla işlem gerektirir. Fonksiyon olarak yetersiz elastikiyet göstermeleri, kenar dayanıkılıı̆ının düşük olması, opak ve cansız görünüm, güneş ışı̆ı ve nemden kolayca etkilenmesi dezavantajlarıdır. $^{8}$

Elastomerler, polivinilklorid, poliüretan ve polisiloksan yıllardır çene-yüz protezlerinde tercih edilmeleri ile önemli yere sahip materyallerdir. Bununla beraber, son yıllarda yeni jenerasyon olarak kullanılan materyaller de bulunmaktadır: ${ }^{47,48}$

\section{Yeni Geliştirilen Çene-Yüz Protez Materyalleri}

\section{Silikon Blok Kopolimeri:}

Silikon elastomerlerin bazı zayıf özelliklerinin geliştirilmesini amaçlayan çalışmaların sonucunda elde edilmişlerdir. Polisiloksanların sahip oldukları avantajların farklı monomerler ile reaksiyona girmesi ile artı özelliklere sahip yeni materyallerin oluşturulması sağlanmıştır. Polidimetil siloksan ve polietilen glikolun çeşitli kombinasyonları olarak üretilmektedirler. ${ }^{49}$

Silikonların yapısının hidrofobik olması doku ile protez arasında uyumsuzluklara neden olabilir. Amfilik yapıdaki kopolimerlerin hidrofilik kısmı iyi ıslanabilirlik ve doku uyumluluğu sağladığı için bu problemi çözebilmektedir. ${ }^{33}$

Avantajları: Yırtılma dirençleri iyidir, bakteri ve mantar gibi mikroorganizmaların gelişimi açısından düşük potansiyele sahiptirler. ${ }^{28}$

Dezavantajları: Uzama yüzdesi yetersiz ve bakteriyel gelişme varlığı gözlenebilen materyallerdir. ${ }^{6}$

\section{Polifosfazenler:}

Esnek protez astar materyali olarak kullanılabilen materyallerdir. İçeriğindeki doldurucu miktarının az olması ve daha yumuşak yapıda olmaları öne çıkan materyal özellikleridir. Yumuşak yapıda olmaları dokuIarın taklit edilmesi açısından önemlidir. ${ }^{33}$ Pigmen- tasyon özelliklerin geliştirilmiş olması neticesinde insan derisi ile mükemmele yakın eşleşme sağlanabilmektedir.

\section{Köpük Silikonlar:}

Silastik 386 olarak tanınan yeni jenerasyon RTV silikonun bir çeşididirler. Yapının içinde baloncuk oluşumu yaklaşık 7 kat kadar hacim artışına sebep olur. Köpük silikonun amacı ve avantajı protezin ağırIığını azaltmaktır. Bununla beraber, yırtılma direnci ve dayanıklılık açısından henüz güvenilir bulunmamaktadırlar. ${ }^{33}$

Sifenilenler diğer bir köpük silikon çeşididir. Metil ve fenil grupları içerebilirler. Kenar dayanıklııkları geliştirilmiş, renklendirilme özellikleri üst düzeyde olan materyallerdir. ${ }^{28}$

\section{Çene-yüz Protezlerinde Renklendirme ve Pigmentasyon}

Çene-yüz protezlerinde gerçekçi görünümü sağlamada renk önemli bir faktördür. ${ }^{40}$ Yapılan çalışmalarda estetik bir yüz protezinin renk ve yumuşaklık özelliklerinin dokuya yakın olmasının hastanın proteze uyum sağlamasında önemli rol oynadığı belirtilmiştir. ${ }^{41}$ Materyale boya maddesi ilavesi ile protezin renklendirmesi sağlanabilmektedir. Protezin renk stabilitesi kullanılan boya ve protez materyalinin özellikleri ile ilişkilidir.

Çene-yüz silikonları gözenekli yapıları ile cilt dokularına yakın bir görünüme sahip materyaller olmakla beraber renksiz olmaları sebebiyle estetik beklentinin karşılanabilmesi için renklendirme işlemi yapıIması gereken materyallerdir. ${ }^{47}$ Çene-yüz silikonları iç ve dış olmak üzere iki farklı sistem kullanılarak veya ikisi beraber kullanılarak renklendirilebilirler. Protezlerin renklendirilmesinde ilk aşama iç boyamadır. Derinin doğal rengi ve konturları eksternal boyama ile sağlanabilmektedir. Renklendirme işleminde çeşitli boyalar ve renklendirici pigmentler kullanılmaktadır, boyalar doğal renklendiricilerden elde edilir ve dimetilbenzen yapısındaki ksilen ile inceltilebilirler. ${ }^{50}$ Opaklık veren özelliği ile kaolin kullanılmaktadır. Bu boyalar su bazlı, silikon bazlı, yağ bazıı ve kuru pigmentler şeklinde bulunmaktadırlar. Bu pigmentlerin içinde metal oksitler bulunmaktadır. Örnek olarak, titanyum oksit, demir oksit, kobalt oksit, bakır oksit verilebilir. Renklendirme işleminde organik pigmentlere göre inorganik pigmentler daha çok tercih edilmektedir. Bu durum inorganik pigmentlerin organik olanlara göre

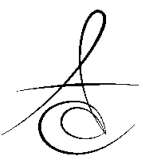


boyamalarının daha kalıcı olması ile ilișkilidir. ${ }^{41}$

Silikon malzemelerin renklendirilmesinde sıklıkla yağ bazlı ve akıcı renklendiriciler kullanılmaktadır. Bu akıcı kıvamdaki renklendiriciler zamanla ve güneş ışığının da etkisiyle içlerinde bulunan sIVı kısmın buharlaşması ile özelliklerini kaybetmektedir. ${ }^{51,52} \mathrm{Bu}$ durum protezlerin 6 ay ile birkaç yıl arasında değişen sürelerde yenilenmesini gerektirebilir. ${ }^{40,53,54}$

Hekimler, çene-yüz protezlerinin renklendirmesinde üretici firmaların önerileri doğrultusunda tercih yapmaktadırlar. Literatürde pigment materyalleri ile ilgili çalışmalar da sitotoksiteyi araştıran çok fazla çalışma bulunmakla birlikte; son zamanlarda silikonlar ve renklendirmeleri ile ilgili yapılan çalışmalarda genellikle renk stabilizasyonunun değerlendirildiği görülmektedir. ${ }^{49,41-56}$

Çeşitli pigment ve opakerlerin yapay yaşlandırma sonrası renk stabilitelerinin araşııııldığı çalışmada baryum sülfatın uzun dönem renk stabilitesi açısından MDX4-4210 silikonu korurken yağ bazlı boyanın baryum sülfat ilavesi olmasa da stabil kalabildiği bildirilmiştir. ${ }^{55}$

Han ve ark..$^{55}$ yaptıkları çalışmada A-2186 silikon ile nano partiküllü oksitlerin $\mathrm{TiO}_{2}, \mathrm{ZnO}, \mathrm{CeO}_{2}$ pigment uygulanmış silikonun renk stabilitesi üzerindeki etkisini, yaşlandırma işleminden önce ve sonra değerlendirmişlerdir. $1 \%$ nano- $\mathrm{CeO}_{2}, 2 \%$ nano- $\mathrm{CeO}_{2}$ ve $2.5 \%$ nano- $\mathrm{TiO}_{2}$ opak olarak kullanıldığında silikonun daha az renk değişikliği gösterdiği gözlenmiş. Sarı silikon pigmentlerinin kullanılarak renklendirildiği silikon materyalinde her üç oksit içinde yaşlandırma işleminin önemli ölçüde silikonun renk stabilitesini etkilediğini gözlemlemişlerdir.

Mancuso ve ark. $^{56}$ yapay yaşlandırma işlemi uygulanan pigment eklenmiş ve eklenmemiş silastic 732 ve silastic MDX4-4210 silikonların renk stabilitelerini kıyaslayan bir araştırma yapmışlardır. Pigment ilavesi olmadan iki silikonun benzer renk değişikliği gösterdiğini bildirmişlerdir.

\section{SONUÇ}

Çene yüz protezleri bütünlüğü bozulan çene ve yüz dokularını rehabilite etmek için yapılan protetik apareylerdir. Geçmişte savaşlar nedeni ile dokuların kaybedilmesi, çene yüz protezlerine olan ihtiyacı ve dolayısıyla materyal gelişimini arttıırken günümüzde iyileşen kanser vakalarına bağlı olarak tedavi intiyacı, materyal gelişimi ile beraber devam etmektedir.

Çene yüz protezlerinde kullanılan materyallerin doku uyumluluğundan, estetiğe kadar çok sayıda niteliğe sahip olması beklenmektedir. Kullanılan materyaller cam, deri, akrilik rezin, akrilik ko-polimer, polivinl klorid ko-polimer, klorlu polietilen, poliüretan, elastomerler, silikon elastomerler olarak devam etmiş her kullanılan materyalin dezavantajı sonrasında geliştirilen materyalde giderilmeye çalışılmıştır.

Günümüzde en çok kullanılan RTV ve HTV silikonların beraberinde blok silikon kopolimerler ve köpük silikonlar gibi yeni formda silikonlar geliştirilmekle beraber polifosfazenler de kullanıma sunulmuştur. Bu geliştirilen yeni materyallerde estetik beklentinin de karşılanması amaçlanmıştır.

Çene yüz protezlerinin estetiği ile ilgili araştırmaların devam ettiği diğer bir konu ise pigmentasyon uygulanarak renklendirilmeleri ile ilgili çalışmalardır. Pigmentasyonlar ile ilgili çalışmalarda genellikle renk stabilitesinin arttırıması ve sitotoksitenin azaltılmasına ihtiyaç olduğu rapor edilmiştir. Günümüzde artan estetik ve fonksiyonel beklentiler, çene yüz protez materyallerinin gelişimini doğrudan etkilemektedir ve gerçeğe daha yakın protezlerin yapımı amaçlanmaktadır.

\section{KAYNAKLAR}

1. Aziza $T$, Watersa M, Jagger R. Analysis of the properties of silicone rubber maxillofacial prosthetic materials. J Dent 2003;31:67-74.

2. Evlioğlu G, Göre E. Yüz Protezi Yapımında Bilgisayar Destekli Teknolojilerin Kullanımı. İstanbul Univ Dişhek Fak Derg 2006;40:1-2.

3. Sipahi C. İmplant destekli çene-yüz protezlerinde retansiyon prensipleri. Gülhane Tıp Derg 2006;48:119-24.

4. Gary JJ, Smith CT. Pigments and their application in maxillofacial elastomers: A literature review. J Prosthet Dent 1998;80:204-8.

5. Davis BK. The role of technology in facial prosthetics. Current Opinion in Curr Opin Otolaryngol Head Neck Surg 2010;18:332.

6. Zardawi FMM. Characterisation of Implant Supported Soft Tissue Prostheses Produced with 3D Colour Printing Technology. A PhD thesis November 2012.

7. Visser A, Raghoebar GM, van Ort RP, Vissink A. Fate of implant retained craniofacial prostheses: 
life span and aftercare. Int J Oral Maxillofac Implants 2008;23:89-98.

8. Pehlivan N, Nemli SK, Karacaer Ö. Çene yüz protezleri ve ekstraoral implantlar GÜ Diş Hek Fak Derg 2011;28: 123-9.

9. Sansoni G, Cavagnini G, Docchio F, Gastaldi G. Virtual and physical prototyping by means of a $3 \mathrm{D}$ optical digitizer: Application to facial prosthetic reconstruction. Virtual Phys Prototyp 2009;4:21726.

10. Lemon JC , Kiat-amnuay S, Gettleman L , Martin JW, Chambers MS. Facial prosthetic rehabilitation: preprosthetic surgical techniques and biomaterials. Curr Opin Otolaryngol Head Neck Surg 2005;13:255-62.

11. Maller US, Karthik KS, Maller SV. Maxillofacial Prosthetic Materials Past and Present Trends. J Ind Aca Dent Spec 2010;1:25-30.

12. Kurtoğlu C, Uzel İ. Geçmişten Bugüne Yüz Protez Materyalleri. CÜ Diş Hek Fak Derg 2008;11:140-4.

13. Oral K, Zini I. Direct wax method for fabrication of three-piece metal molds. J Prosthet Dent 1978; 40:558-62.

14. Deba K, Yunus N, Tamrakar AK. Oral\&Maxillofacial Prosthetics-I: Objectives \& History Heal Talk 2012;4:18-20.

15. Barnhart GW. A new material and technic in the art of somatoprosthesis. J Dent Res 1960;39:83644.

16. Gonzalez JB. Polyurethane elastomers for facial prostheses. J Prosthet Dent 1978;39:179-87.

17. Lontz JF. State-of-the-art materials used for maxillofacial prosthetic reconstruction. Dent Clin North Am 1990;34:307-25.

18. Chalian VA, Philips RW, Conroy B, Haylock C, Hulterstrom AK, Pratt G, Winter RW. Materials in maxillofacial prosthetics. J Biomed Mater Res. 1974;5:349-63.

19. Conroy C, Haylock BF, Hulterstrom C, Pratt A, Winter GR. Report on a four year research and development programme involving the Institute of Maxillofacial Technology and the University of Wales Institute of Science and Technology aimed at the production of a new facial prosthetic system in: Conroy BF Ed. Proceedings of the Institute of Maxillofacial Technology London. 1979:218-245.

20. Wolfaardt JF, Chandler HD, Smith BA. Mechanical properties of a new facial prosthetic material J
Prosthet Dent 1985;53:228-34.

21. Farah JW, Robinson JC, Koran A, Craig RG, Hood JA. Properties of a modified cross-linked silicone for maxillofacial prostheses. J Oral Rehab 1987; 14:599-602.

22. Mugan N, Tuncer EB, Keskin H, Özdemir T. İki burun epitezi. İst Ünv Diş Hek Fak Derg 1979;12:281-3.

23. Beumer J, Curtis T, Marunick M. Maxillofacial Rehabilitation. Prosthodontic and Surgical Considerations. 3 ed. St Louis. Inc.1996.p.377455.

24. Hooper SM, Westcott T, Evans PLL, Bocca AP, Jagger DC. Implant-Supported Facial Prostheses Provided by a Maxillofacial Unit in a U.K. Regional Hospital: Longevity and Patient Opinions. J Prosthodont 2005;14:32-8.

25. Ariani N, Visser A, van Oort RP, Kusdhany L, Rahardjo TB, Krom BP, van der Mei HC, Vissink A. Current state of craniofacial prosthetic rehabilitation. Int J Prosthodont 2013;26:57-67.

26. Atay A, Günay Y. Çene-Yüz Protezlerinde Bakım. Atatürk Üniv Diş Hek Fak Derg 2007;2:22-5.

27. Keyf F. Change in a maxillo-facial prosthesis material effecting from environmental factors: a clinical report. J Biomaterials Applications 2002;16:259-66.

28. Deba K, Yunus N, Tamrakar AK. Oral\&Maxillofacial Prosthetics-II: Materialistic Approach. Heal Talk 2012;4:18-20.

29. Craig RG, Powers JM. Restorative Dental Materials. 11 ed. Mosby, St Louis, 2002.p. 68-108, 675-680, 186-95.

30. Shah D, Vaishnav K, Agrawal P. Materials used in maxillofacial prosthesis: a review. Int J Res Dent 2014;4:1-5.

31. Lewis DH, Castleberry DJ. An assessment of recent advances in external maxillofacial materials. J Prosthet Dent. 1980 ;43:426-32.

32. Kiat-amnuay $S$, Jacob RF, Chambers MS, Anderson JD, Sheppard RA, Johnston DA, Haugh GS, Gettleman L. Clinical Trial of Chlorinated Polyethylene for Facial Prosthetics Int J Prosthodont 2010;23:263-70.

33. Mitra A, Choudhary S, Garg H, Jagadeessh HG. Maxillofacial prosthetic materials an inclination towards silicones. J Clin Diagn Res 2014;8:8-13.

34. Robert GC, Powers JM. Restorative Dental

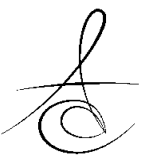


Materials. 11 ed. Philadelphia Mosby, Inc. 2002.p. 348-65.

35. Çevik P, Eraslan O. Çene Yüz Protezlerinde Kullanılan Materyaller Ve Bu Konudaki Gelişmeler Atatürk Üniv Diş Hek Fak Derg 2015;10:141-147.

36. Murata H, Hong G, Hamada T, Polyzois GL. Dynamic mechanical properties of silicone maxillofacial prosthetic materials andthe influence of frequency and temperature on their properties. Int J Prosthodont 2003;16:369-74.

37. Parel SM, Holt $R$, Brånemark $P$, Tjellström A. Osseointegration and Facial Prosthetics. Int J Oral Maxillofac Implants 1986;1:27-9.

38. Craig RG, Powers JM, Wataha JC. Dental materials properties and manupulations. 8 ed. St Louis: Mosby; 2004.p.15-37.

39. Young RJ, Ovell PA. Introduction to Polymers. 2 nd Ed, London: Chapman and Hall, 1991.p.241-50.

40. Aydıntay K, Korkmaz T, Coşkun A, Yılmaz C, Yaluğ S. Renklendirilmiş ve Renklendirilmemiş maksillofasiyal elastomerlerine ultraviyole ışığı verilmesi-ile oluşan renk değişiklerinin incelenmesi. CÜ Diş Hek Fak Derg 2004;7:11-9.

41. Yazıcıoğlu H, Aytaçoğlu S. Yüz Protezi Yapımında Kullanılan Materyallerin Sertlik, Çekme Dayanıklıı̆ı ve Uzama Değerlerine Eksternal Boyanın Etkisi. GÜ Diş Hek Fak Derg 2001;18:137-42.

42. Çevik P. Silika Ve Titanyum Dioksit İlavesinin İki Farklı Maksillofasiyal Silikon Elastomerin Mekanik Özelliklerine Etkisi. Doktora Tezi, SÜ Sağlık Bilimleri Enstitüsü, Konya, 2013.

43. Uyan D. Yüz protezleri yapımında kullanılan iki farklı tip silikon elastomerin in vivo implantasyon tekniği ile biyolojik uyumluluk açısından kıyaslanması, Doktora tezi, İstanbul Üniversitesi, 2006.

44. Kenneth J. Anusavice. Phillips' science of dental materials. 11 ed. St.Louis: Saunders Elsevier; 2009.p.235-55.

45. Hulterstrom AK, Berglund A. Wettability, water sorption and water solubility of seven silicone elastomers used for maxillofacial prostheses. ] Mater Sci 2008;19:225-31.

46. Waters MGJ, Jagger RG, Winter RW. Effect of surface modified fillers on the water absorption of a RTV silicone denture soft lining material. J Dent 1996;24:297-300.

47. Atay A, Ural AU. Çene-yüz silikonlarıyla kullanılan renklendirme pigmentlerinin sitotoksisiteleri. G TIp Derg 2013;55:171-5.

48. Eleni PN, Krokida M, Polyzois G, Gettleman L, Bisharat GI. Effects of outdoor weathering on facial prosthetic elastomers. Odontology 2011;99:68-76.

49. P Böhm. Functional Silicones and SiliconeContaining Block Copolymers Dissertation Zur Erlangung des Grades "Doktor der Naturwissenschaften "Im Promotionsfach Makromolekulare Chemie am Fachbereich Chemie, Pharmazie und Geowissenschaften der Johannes Gutenberg-Universität Mainz, 2012.

50. Haug SP, Andres CJ, Moore BK. Color stability and colorant effect on maxillofacial elastomers. Part I: Colorant effect on physical properties. J Prosthet Dent 1999;81:418-22.

51. Günay $Y$, Atay A, Karayazgan B, Oruç S. Yüz protezlerinin kullanım sürelerinde etkili olan klinik faktörler: iki olgu sunumu. Gülhane Tıp Derg 2009;51:182-5.

52. Lemon JC, Chambers MS, Jacobsen ML, Powers JM. Color stability of facial prostheses. J Prosthet Dent 1995;74:613-8.

53. Kantola R, Lassila LV, Tolvanen M, Valittu PK. Color stability of thermochromic pigment in maxillofacial silicone. J Adv Prosthodont 2013;5:75-83.

54. dos Santos DM, Goiato MC, Moreno A, Pesqueira AA, Haddad MF. Influence of pigments and opacifiers on color stability of an artificially aged facial silicone. J Prosthodont 2011;20:205-8.

55. Han Y, Zhao Y, Xie C, Powers JM, Kiat-amnuay S. Color stability of pigmented maxillofacial silicone elastomer: effects of nano-oxides as opacifiers. J Dent 2010;38:100-5.

56. Mancuso DN, Goiato MC, Santos DM. Color stability after accelerated aging of two silicones, pigmented or not, for use in facial prostheses. Braz Oral Res 2009;23:144-8.

\author{
Yazışma Adresi \\ Yrd.Doç.Dr. Serkan SARIDAĞ \\ Kocaeli Üniversitesi, \\ Diş Hekimliği Fakültesi \\ Protetik Diş Tedavisi A.D, \\ 41300 Kocaeli, Türkiye \\ e-mail: ssaridag@hotmail.com
}

